\title{
What is a REDD+ pilot? A preliminary typology based on early actions in Indonesia
}

\author{
Erin Myers Madeira, Erin Sills, Maria Brockhaus, Louis Verchot and Markku Kanninen
}

\section{Key Points}

- This infobrief provides an early snapshot of 17 REDD+ pilots under development in Indonesia in mid 2009.

- There is great variety in and experimentation by the proponents of REDD+ pilots.

- Three key dimensions useful for categorising early pilots are: 1) degree of spatial planning and heterogeneity of forest classification, 2) strategy for establishing long-term claims to carbon, and 3) predominant driver and agent of deforestation and degradation.

- The prevalence of the concession model in this sample of REDD+ pilots is explained by its alignment with existing tenure regimes and with the requirement to demonstrate secure, long-term carbon tenure in order to sell credits in voluntary carbon markets.

- REDD+ pilots following the concession model risk carrying forward biases and constraints of the existing concession system, including the focus on production forests and the tendency to exclude smallholders from management decisions. Addressing the inequalities and inefficiencies of the existing tenure regime requires broader policy reform and larger-scale action than is likely to be achieved by individual pilots.

- High transaction costs deter the development of pilots that partner directly with smallholders to reduce emissions. New models and strategies should be developed to reduce these transaction costs, for example, by aggregating or bundling smallholder initiatives.

- Further research is needed both to assess outcomes of different pilot types and to update this typology to reflect the rapidly expanding number of REDD+ pilots and the rapidly evolving institutional and regulatory framework for REDD+ in Indonesia.

\section{Introduction}

In 2007, the parties to the United Nations Framework Convention on Climate Change (UNFCCC) agreed to the Bali Roadmap, which encouraged actors in developed and developing countries to take immediate actions to mitigate carbon emissions from the forestry sector. Policymakers, investors, donor organisations and NGOs responded by initiating a number of activities to reduce emissions from deforestation and forest degradation and promote the conservation, sustainable management of forests and enhancement of forest carbon stocks in developing countries (UNFCCC Decision 2/CP.13-11), commonly called 'REDD+'. Without a negotiated agreement within the UNFCCC, it is uncertain what an international REDD+ programme will include. Despite this uncertainty, development of REDD+ activities continues. For example, WertzKanounnikoff and Kongphan-Apirak (2009) identified 109 REDD+ activities worldwide: 44 demonstration activities that seek to directly reduce emissions from deforestation and degradation and 65 readiness activities designed to create an enabling framework.

With $56 \%$ of its emissions coming from deforestation, degradation and peatland conversion, and a commitment to reduce its emissions by $41 \%$ below 'business as usual' trajectories by the year 2020 conditional on assistance from the international community (Boer et al. 2010), Indonesia will be an important supplier in any international REDD+ regime. The Government of Indonesia (Gol) has been supportive of REDD+ in international and bilateral negotiations and is proactive domestically in establishing a regulatory framework for subnational REDD+ activities. Key actions include the formation of the Indonesian Forest Climate Alliance in 2007, and the establishment of the cross-ministerial National Climate Change Council (Dewan Nasional Perubahan Iklim, or DNPI) in 2008. In 2009, the Ministry of Forestry established procedures for reducing emissions from deforestation and forest degradation via Permenhut 30, Menhut II/2009, which defines participants, forest types, roles of project proponents and different levels of government for REDD+ interventions (Atmadja and Wollenberg 2010), and for licencing commercial use of carbon sequestration and storage in production and protected forests (Permenhut 36, Menhut II/2009). In May 2010, the governments of Indonesia and Norway signed a Letter of Intent to cooperate on REDD+. It is not clear how the different regulatory measures will be implemented and whether future Ministry of Finance actions will supersede existing Ministry of Forestry regulations. Despite the regulatory complexity and lack of clarity in the national institutional architecture, investors and donors have invested in over 30 REDD+ pilots (CIFOR 2010).

In this infobrief, we propose a typology of REDD+ pilots in Indonesia based on analysis of the initial structure (in mid-2009) of 17 pilots, and we discuss possible reasons for the prevalence of certain types. This typology is intended to facilitate understanding, sharing of early lessons and the design of future research on REDD+ pilots. 


\section{Early REDD+ pilots in Indonesia}

We define REDD+ pilots ${ }^{1}$ as activities 1) aimed at directly reducing emissions from deforestation and degradation in geographically distinct and contiguous areas, which are 2) identified by their proponents as REDD+ and 3) are operating under official agreements with some level of government.2

Our results are based on an assessment of REDD+ pilots across four islands (12 in Kalimantan where the research focused, 2 in Sumatra, 2 in Papua, and 1 in Sulawesi), strategically selected to represent the major forest types, deforestation drivers, and types of project proponents engaged in REDD+ in Indonesia. As of mid 2009, each of these 17 pilots had passed the concept stage, but was still in a planning or early implementation phase. In contrast to the pilots listed in CIFOR (2010), our sample includes a larger proportion of the pilots being developed in Kalimantan and Papua, and of the pilots operating at the landscape scale as described below. Our sample includes three of the four REDD+ pilots that were recognised as 'demonstration activities' by Gol by February 2010 (Government of Indonesia 2010).

Our assessment of these pilots is based on a review of project documents, semi-structured interviews with project proponents, ${ }^{3}$ and 21 open-ended interviews with project partners, key experts and stakeholders, conducted by the first author between February and September 2009. Thus, primarily we captured the perspectives and intentions of project proponents, including various coalitions of international NGOs, Indonesian and foreign investors, private companies specialising in REDD+ project development, agribusiness and timber companies, Gol, and bilateral aid organisations that are partnering with Gol. For each pilot, we collected data on location, size, legal classification of forest, degree of spatial planning, strategy for establishing long-term claim to carbon, type of threat (driver of deforestation and degradation), agent of deforestation or degradation, response to threat, shortterm activities, long-term activities, standards pursued, market targeted, cobenefits, timeline, and types of project proponents. Of these, five variables were used to establish the typology proposed here.

The REDD+ pilots examined in this study are considering implementing a range of activities, including positive incentives, land swaps, agroforestry, rehabilitation of degraded forests and peatlands, best practices for timber and plantation operations, and elements of spatial planning. Thirteen of the 17 (76\%) pilots plan to seek third-party validation using both Voluntary Carbon Standard (VCS) and Climate Community and Biodiversity Alliance (CCBA) standards. In order to obtain this validation, some pilots are developing new avoided deforestation methodologies (VCS 2010) which are subject to a dual validation process under the VCS guidelines (www.V-c-s.org).

Because of significant uncertainty about the specific activities and benefit-sharing systems that would be implemented in the REDD+ pilots, we focused on their initial structural decisions about basic strategies for reducing carbon emissions. There is great variation and experimentation in the structure of these pilots. We identified key dimensions in which there is variation and which in turn helped to define different pilot types. While this typology is based only on features of pilots that are decided early in their development, these early structural decisions are important because they shape the available pathways for implementation. Outcomes will also be influenced by project management and later implementation decisions, as well as the changing institutional and regulatory frameworks within which REDD+ projects are designed, developed and validated. However, we believe that the early structural decisions provide a useful way to characterise pilots and will influence their implementation pathways.

\section{Typology of REDD+ pilots}

\section{Degree of spatial planning and heterogeneity of forest classification}

REDD+ pilots can be categorised as site-level or landscape-level, on the basis of the extent to which they incorporate spatial planning and whether the pilot covers forest areas with different legal classifications. VCS requires that all types of pilots must have clearly defined boundaries in order to measure emissions reductions and removals. Landscape-level pilots aim to reduce net emissions from heterogeneous landscapes covering various land uses and legal classifications of the forest. They incorporate multiple land uses and may include active timber or mining concessions. Landscape-level pilots actively engage in the spatial planning process, which requires collaboration and support from the local government and relevant provincial and national Gol ministries. They typically encompass large areas within which various deforestation drivers are present, and they typically undertake several measures to reduce emissions and increase removals in specific sub-areas. For example, a landscape-level pilot could engage with the spatial planning process in a district to channel expansion of oil palm and other plantations onto degraded lands and restrict emission-intensive operations in old-growth forests, while at the same time promoting best management practices in timber concessions and directly supporting conservation of high-value areas. Thus, a landscapelevel pilot may not actively manage its entire area for carbon.

In contrast, site-level pilots target a specific area where the forest has a homogenous legal classification (e.g., 'Production Forest', 'Conversion Production Forest') or, in rare cases, two closely related classifications). The entire forest area of site-level pilots is actively managed to reduce emissions. Site-level pilots are typically smaller than landscape-level pilots, although there are exceptions. A sitelevel pilot also requires approval of relevant Gol officials and must be consistent with the spatial plan. However, unlike landscapelevel pilots, site-level pilots generally take the spatial plan as given: they are manifestations of the spatial plan, rather than influences on that plan. This does not mean that the proponent and other organisations working with site-level pilots do not engage with the government; in fact, they may actively seek to shape local regulations for REDD+ pilots, including the spatial plan. However, the outcomes of this political engagement do not count towards the pilots' impacts on net carbon emissions. 


\section{Strategies for establishing carbon claims}

To sell carbon credits, a project proponent must demonstrate a long-term legal claim to the carbon. For example, VCS requires that project proponents have proof of title that demonstrates their 'right to the GHG [greenhouse gas] emission reductions ... and the ownership of the project' (VCS 2008a).

Within the complex and evolving regulatory context in Indonesia, the options for establishing carbon claims are largely defined by the existing forest land tenure system. Almost the entire Indonesian forest estate is administered by the Gol under statutory law. Less than $6 \%$ of the forest estate is either formally designated for use by communities or indigenous peoples or owned by firms or individuals (Sunderlin et al. 2008; Hinrichs et al. 2008). Although buying and selling forest lands is prohibited, there are other wellestablished options for acquiring legal claims to forest resources for example, through timber and agricultural concessions. However, 'carbon rights' are not explicitly addressed in existing regulations, and there is no clear path to demonstrating a legal claim specifically to carbon. Despite this lack of clarity, project proponents are investing in the development of REDD+ pilots, demonstrating their confidence that they will be able to establish a legal longterm claim to carbon. To establish such long-term carbon claims, proponents in Indonesia use one of four strategies.

1. The concession model. Forest concessions are widely used throughout the tropics for both harvesting of forest products and management of forest resources - in both cases, primarily for timber. The basic underlying logic is that 1) because forests provide a range of public goods and services, they should remain under public ownership, but 2) governments do not have capacity, capital or experience to efficiently manage and harvest timber (Gray 2002). However, the Indonesian timber concession system (HPH) has long been criticised for inefficient allocation of contracts, failure to capture the full stumpage value of timber, and inadequate safeguards for non-timber benefits. These criticisms precipitated reforms in the late 1990s, including increased fees, fewer market restrictions, and decentralisation of the process of allocating small concessions, followed by a partial reversal of that policy in the mid 2000s as degradation and deforestation continued apace (Barr et al. 2006; Resosudarmo 2004). In Indonesia, timber supply also depends on a parallel concession system for establishment of industrial timber plantations (HP-HTI), including short-term licences to clear cut forest areas designated as degraded and destined for forest plantations (IPK).

Some proponents in Indonesia have opted to acquire concession rights to the area of forest covered by their pilots. This may be a traditional timber harvesting concession, under which the proponent or partner will implement more sustainable forest management such as reduced-impact logging. However, the more common strategy, pursued by seven of the eight concession-model pilots, is to obtain an Ecosystem Restoration Concession (ERC) or a province-specific equivalent of the ERC in Papua. The Ministry of Forestry established the ERC option for degraded production forests in 2007. The concession holder is obliged to perform some restoration activities and has the right to generate revenues from carbon and other payments for environmental services, conditional on complying with licencing requirements being developed under the evolving regulatory framework. ERCs can be obtained only for forest areas classified as production and production-conversion forests, and require multiple approvals from district, provincial and national authorities (e.g. for environmental impact assessments, and local stakeholder consultation). Aceh and Papua provinces have special autonomous status. In Papua, some project proponents are working with the governor's office to explore whether they can create a provincial equivalent to the ERC that would not require approval by as many levels of government. The ERC system allows the establishment of long-term $(60+35$ years) tenure security. This seems to be very attractive in the context of REDD+, despite the fact that the transaction costs to establish such a concession are similar to those for timber and conversion concessions.

2. Land user partnerships. A proponent may enter into an agreement with existing land users to develop and share the carbon credits from a pilot. The project proponent never establishes independent legal rights to the land or carbon, but enters into a contractual agreement with a land user who has legally recognised rights to land and therefore is assumed also to be able to obtain rights to the carbon. The project proponent agrees to develop the pilot in exchange for a share in the resulting carbon benefits. For example, these land users may be legal timber concession holders who could improve their environmental performance by implementing reduced impact logging or sustainable forest management, oil palm concession holders who could set aside some of their existing concession area to protect high conservation value forest, or local stakeholders who could reduce forest clearing by engaging instead in small-scale sustainable forest management or expanding agroforestry practices.

3. Government partnership. A proponent may enter into an agreement with Gol to develop a REDD+ pilot and share the carbon credits produced by the pilot interventions. Similar to the other partnership model, the project proponent does not establish its own legal rights to the land or carbon, but rather enters into a contractual agreement to develop the pilot in exchange for a share of the carbon benefits. For example, a proponent may partner with a district government to improve management of a protected forest area.

4. No carbon rights. In this case, the 'proponent' is really supporting the government to implement REDD+ activities, and Gol (at the national, provincial or district level) will hold all the rights. Although the external proponent organisation is actively developing the REDD+ pilot - and, arguably, without the external proponents there would be no REDD+ intervention - it does not seek a share of the carbon rights. 


\section{?}

\section{Predominant driver and agent of deforestation and degradation}

REDD+ pilots in this study sample are addressing two sets of drivers and agents: 'planned' deforestation and degradation by industrial-scale agents, and 'unplanned' deforestation and degradation by smallholders. According to VCS, 'planned' deforestation and degradation is designated or sanctioned by the government and is included in land-management or spatial-planning documents (VCS 2008c). In Indonesia, it can take a number of forms, including conversion of forest to industrial-scale production of commodities such as palm oil, rubber and wood pulp, and mining interests. 'Unplanned' deforestation and degradation is unsanctioned, results from the inability of institutions to control forest use, and includes encroachment on forest areas designated for protection, for timber extraction or other purposes (VCS 2008c). Unplanned deforestation and degradation includes forest loss due to illegal activities. Both planned and unplanned deforestation can be carried out by smallholder and industrial-scale agents: an example of unplanned deforestation by industrial-scale agents is unsanctioned expansion of plantations; meanwhile the Transmigration programme provides an example of planned deforestation by smallholders that is sanctioned by the state. In practice, all of the site-level REDD+ pilots in our sample opted to focus on either planned deforestation by large agribusiness and timber firms or unplanned deforestation by agricultural households, local logging operations and other smallscale actors. All of the landscape-level pilots address both, and through the spatial planning process some also address unplanned industrial-scale and planned smallholder deforestation.

Combining these three dimensions identifies different types of REDD+ pilots among the sample of 17 (Table 1).

One might expect that the type of organisation financing the pilot (e.g. environmental NGO, bilateral aid agency and privatesector investor) would be related to these initial structural decisions, but we did not find any consistent patterns (results available from lead author). This may be because there are large and shifting coalitions of organisations involved in many of the pilots, making it difficult to discern such patterns at this early phase of pilot development.

\section{Motivations for different types of REDD+ pilots}

REDD+ pilots are clearly not distributed evenly across all possible types (Table 1). While acknowledging that the number and types of pilots continue to evolve rapidly, we believe that our sample shows some early tendencies that are informative. In this section, we consider possible reasons for these tendencies.

\section{Landscape-level pilots 'owned' by Gol can adapt to a changing regulatory environment}

Landscape-level pilots have at least three important advantages: they cover a large area with a large stock of carbon and so have the potential to have a large impact on emissions; they have a clear path to integrate with future national REDD+ policies and low-carbon development plans; and they internalise and thereby perhaps more effectively manage (but not eliminate) leakage. However, they are correspondingly complex to establish, implement and monitor. By definition, the proponents of landscape-level pilots collaborate with the government to integrate priorities for low-carbon land use into the spatial planning process across a large area. Thus, they logically address both planned and unplanned deforestation. Three of the five landscapelevel pilots do not claim any carbon rights themselves and are financed by bilateral aid organisations or large (conservation) NGOs that are partnering with multiple levels of the Indonesian government to develop official demonstration activities. A key advantage of this approach is its ability to adapt to a changing regulatory environment.

\section{Table 1. Typology of REDD+ pilots}

\begin{tabular}{|c|c|c|c|c|}
\hline \multirow[t]{2}{*}{ Landscape or site level } & \multirow[t]{2}{*}{$\begin{array}{l}\text { Strategy to establish legal } \\
\text { carbon rights }\end{array}$} & \multicolumn{2}{|c|}{$\begin{array}{l}\text { Predominant driver and agent of } \\
\text { deforestation and degradation }\end{array}$} & \multirow[t]{2}{*}{ Tota } \\
\hline & & $\begin{array}{l}\text { Planned by industrial- } \\
\text { scale actors }\end{array}$ & $\begin{array}{l}\text { Unplanned by } \\
\text { smallholders }\end{array}$ & \\
\hline \multirow[t]{2}{*}{ Landscape } & Government partnership & & Both & 2 \\
\hline & No carbon rights & & Both & 3 \\
\hline Total Landscape-level & & & & 5 \\
\hline \multirow[t]{4}{*}{ Site } & Concession model & 8 & 0 & 8 \\
\hline & Land user partnership & 2 & 0 & 2 \\
\hline & Government partnership & 0 & 1 & 1 \\
\hline & No carbon rights & 0 & 1 & 1 \\
\hline Total site-level & & 10 & 2 & 12 \\
\hline Total & & & & 17 \\
\hline
\end{tabular}


Transaction costs and reputational risks are an important factor in how site-level pilots are structured. Relatively few proponents partner with either land users or the government for site-level pilots, most likely because of the high transaction costs. Of the three pilots pursuing partnership strategies, one partners with an oil palm concession, one with a timber concession, and one with a district government with authority over a protected forest. Interviews revealed that transaction costs discouraged more pilots from pursuing the partnership model. Bureaucratic hurdles to working with government and logistical hurdles to working with a large number of smallholders were mentioned as drawbacks to this approach. Proponents have more actively pursued partnerships with industrial-scale actors, who are both less bureaucratic and less numerous. In fact, proponents had attempted to develop more partnership-based pilots with industrial-scale land users, but found it difficult to reach mutually agreeable terms and overcome concerns about reputational risks from collaborating with agribusiness or timber companies who may have illegitimately acquired concessions and/or unjustly negotiated (or not negotiated at all) with smallholders.

By far the most common approach to establishing a long-term claim to carbon is to obtain a concession. In seven of the eight pilots adopting this approach, the proponent is using an ERC (or provincial equivalent). The process of acquiring an ERC involves the district, provincial and central governments, and multiple layers of decision-making at these different levels. Thus, the transaction costs of this strategy are also significant-in fact, most pilots had not yet obtained final approval of their ERCs by September 2010. However, the strategy is popular because, although early transaction costs are significant, pilots with concessions will not face the ongoing transaction costs associated with partnership negotiations.

No pilots in this study sample are seeking to establish their claim to carbon via partnerships with smallholders. Interviews indicated that high transaction costs to negotiate with multiple diffuse actors discouraged the adoption of this model.

\section{Long-term tenure security is important for validation and cost}

recovery. Certainty about the longevity of the pilot (or permanence of the carbon claim) is also a key factor in favour of the concession model. Most proponents are interested in ensuring that the pilot will last long enough to recover the large upfront costs. And, in order to obtain VCS validation, the proponent must adequately address risks of non-permanence, including risks from unclear land tenure and potential land-tenure disputes (VCS 2008b). Further, security of tenure is paramount to Indonesian and foreign investors. An ERC allows the proponent to claim with reasonable certainty that they have tenure security for 60 years, renewable for an additional 35 (assuming they remain in compliance with relevant regulations); timber and plantation concessions similarly allow proponents to claim that their pilots will continue for a known duration. Thus, compared to the alternative partnership models for establishing a claim to the carbon, the concession model may appear to be the best way to establish clear long-term carbon claims. In practice, project proponents have encountered competing claims to the same land by different stakeholders (sometimes recognised by different levels of government), which have complicated and prolonged the concession application process. Whereas the project proponent adopting the concession model has a recognised legal claim to the land (and hence an implied claim to the carbon, subject to licencing requirements), there is less certainty in the partnership models in which the project proponent shares control of the pilot, and the partner (a concession holder or district government) alone holds the right to the land. While carbon is the top priority of project proponents, their partners must balance other priorities including oil palm production, timber volumes and constituent interests. If these priorities conflict in the future, the partners may seek to renegotiate agreements, increasing transaction costs and threatening the project proponent's carbon claim.

\section{The existing tenure regime and forest classification system shapes prevalence of pilot types. ERC is applicable only in} production and production-conversion forests, and there is not currently an equivalent mechanism that can be used by project proponents to develop REDD+ pilots in other forest types or non-forest areas. Thus, if the concession model remains the most appealing way for proponents to establish long-term claims to carbon, Indonesia could see most REDD+ pilots developed in production forest even though emissions come from all forest types and actor groups.

Historically, the land tenure regime in Indonesia has favoured large-scale enterprises, and there is a well-established and welltested system of forest concessions (Agrawal et al. 2008). The concession model is consistent with the existing tenure system and thus has provided enough certainty to allow REDD+ pilots to move forward in advance of a national programme. However, because the concession model is adapted to the existing tenure and governance system, it seems unlikely that implementation of REDD+ pilots using this model will effectively address the inequalities and other flaws of the existing system.

In Indonesia, tenure rights of smallholders are often not recognised. As a result, even if a pilot could overcome the transaction costs of working with multiple smallholders, it might not be able to demonstrate the chain of custody of land and carbon that is required by investors and for validation by leading standards. REDD+ is often conceptualised as a form of payments for ecosystem services (PES): voluntary, conditional transfers from beneficiaries to providers of ecosystem services (Sills et al. 2009). The absence of recognised rights for smallholders and indigenous peoples has slowed the development of PES schemes in Southeast Asia (Wertz-Kanounnikoff and Kongphan-Apirak 2008) and is similarly an obstacle to the development of REDD+ pilots in Indonesia that base their claims to additional, permanent avoided emissions on agreements and programmes (such as PES) focused on smallholders.

\footnotetext{
Additionality requirements may explain the absence of pilots focused on unplanned deforestation and degradation by industrial-scale actors. Validation under VCS requires that pilots demonstrate 'additionality', meaning that the emissions reductions are additional to what would occur if there was no intervention. Specifically, the VCS requires that the intervention is 'not mandated
} 
by any enforced law, statute or other regulatory framework', among other criteria (VCS 2008a). No site-level pilot focuses on stopping unplanned deforestation and degradation by industrial-scale actors even though this is a driver of emissions, for example, via plantations' unsanctioned expansion into adjacent forest areas. The absence of this pilot type may be due to the difficulty of proving additionality, above and beyond what is technically required and should be possible to enforce under Indonesian law. Pilots that address unplanned activities by smallholders may be more able to address additionality by making the case that these activities are relatively more difficult to monitor and regulate.

\section{Future research needs and implications for REDD+ design in Indonesia}

Using three key dimensions of the early structure of REDD+ pilots, we have identified six types of pilots in Indonesia. Research that tracks the performance of these pilot types and analyses their ability to efficiently, effectively and equitably deliver emissions reductions and environmental and social cobenefits over time can inform decisions about which types of pilots should be scaled up and replicated in which situations.

The most common type of pilot relies on the concession model to avoid planned deforestation by industrial-scale agents. This is consistent with the importance of intensive agriculture and plantations as key drivers of deforestation and degradation in Indonesia (Butler and Laurance 2008). However, the concession model can only be used in production and production-conversion forest. For REDD+ pilots to address industrial-scale drivers in other forest types, new or modified strategies must be developed for other forest types and areas outside the legally defined forest estate.

Small-scale and subsistence agriculture is also an important driver of deforestation and degradation, but this driver is being addressed only to a very limited degree by site-level pilots. For pilots to address deforestation due to small-scale and subsistence agriculture, measures must be taken to reduce transaction costs and to overcome the difficulties in monitoring, enforcement and validation methodologies.

Transaction costs deter the development of pilots that partner with smallholder farmers to reduce emissions. Gol, NGOs and donor organisations could develop models and strategies to reduce transaction costs, perhaps by aggregating smallholders and grouping smallholder projects, and thus improve the cost efficiency and encourage the development of new or modified types of pilots that more directly engage smallholders.

REDD+ pilots modelled after PES schemes, where smallholders provide the service of emissions abatement, have the potential to help alleviate poverty for participating communities (Peskett et al. 2008; Wunder et al. 2008). These schemes require that smallholders have control over their resources; yet the rights of smallholders are often not recognised in Indonesia. As a result, pilots seeking to work with smallholders as service providers find it difficult to demonstrate the long-term tenure that is required for obtaining validation and attracting investors. In contrast, industrial-scale actors often have officially recognised rights to forests in the form of concessions issued by Gol, and therefore it is easier to consider and compensate industrial-scale actors as the service providers. NGOs and donor organisations can help Gol create an enabling environment for REDD+ pilots that provide PES to smallholders by increasing the long-term security of the rights of smallholders.

Carbon savings are just one of the benefits expected from REDD+. The draft text on REDD+ of the Ad Hoc Working Group of Longterm Cooperative Actions under UNFCCC specifically states that REDD+ activities should contribute to sustainable development and the reduction of poverty (UNFCCC 2009). Thirteen of the 17 pilots in this study are pursuing accreditation by the Climate, Community and Biodiversity Alliance (CCBA) standards that require pilots have a net positive impact on communities (CCBA 2008). All the project proponents that we interviewed stated that improving local livelihoods is a priority. Many pointed out that investment in livelihoods is critical to the long-term sustainability of their pilots. Several proposed projects are already seeking to deliver concrete benefits to smallholders by employing them in enforcement or in activities to restore degraded forest and peatland. However, very few of the pilots have even begun implementation, and many still have a list of possible implementation activities that fit within their initial, established structure. Many of the elements that will most affect poverty alleviation are not determined by the core structure for offsetting carbon emissions, and thus actual outcomes in this area are unknown and may be influenced by future management and implementation decisions independent of project type as defined here. Future research should analyse whether certain pilot types more successfully achieve poverty alleviation goals.

The pilots in this study have developed REDD+ strategies within the constraints of the existing tenure regime. As a result, they may not be well positioned to take the lead on resolving inequalities embodied by that regime. There is clearly a risk that the limitations of the existing tenure system will be replicated in a future REDD+ system. Addressing this requires broad policy reforms well beyond the scope of individual REDD+ pilots, for example, in the realm of regulations and requirements for local benefit sharing and co-management of concessions. Efforts at such policy reforms in the past have not been entirely successful, but REDD+ creates an opportunity and urgency to try again. National programmes may be best positioned to address inequalities and inefficiencies in the existing tenure regime, and may be required in addition to pilot activities, either to encourage a wider variety of pilot types or to reform the basic concession model in Indonesia.

Three of the five landscape-level pilots do not claim any carbon rights themselves and are driven by bilateral aid organisations or large international NGOs that are partnering with multiple levels of the Indonesian government to develop official demonstration activities. This approach has the advantage of being highly 
adaptable to a changing regulatory environment. If Gol develops a strong national REDD+ programme, the landscape-level pilots in which project proponents do not claim carbon rights may be better able to adapt to the developing REDD+ regulatory framework because they are 'owned' by Gol and are integrated into the spatial planning process. By integrating landscape-level pilots into spatial plans and economic development strategies, such as the low-carbon growth plans that are being developed in at least three provinces, REDD+ can become part of long-term development pathways.

\section{Conclusion}

This infobrief presents a snapshot of proponent perceptions and emerging types of REDD+ pilots in Indonesia in 2009. CIFOR is continuing research on a smaller sample of these first-generation pilots, as part of the Global Comparative Study of REDD+. The typology proposed here helped inform that research, which is taking the critical next step of rigorously assessing the impacts of pilots on local livelihoods and land use.

REDD+ pilots in Indonesia are serving the purpose imagined in the Bali Road Map, demonstrating how national REDD+ programmes could be implemented at the local level, as well as illustrating the challenges and the need for reform of the existing institutional, regulatory and land-tenure systems. This regulatory and institutional framework for REDD+ is evolving rapidly in Indonesia, presenting ample opportunities to incorporate lessons generated by the pilots. The Indonesia experience with REDD+ pilots also offers global lessons on some alternative ways to structure sub-national activities, how those alternatives are shaped by institutional and governance conditions, and-looking to the future-on the impact pathways and outcomes of different types of REDD+ pilots.

\section{Notes}

1. In the global policy discussion about REDD+, the term 'pilot' has many different definitions and implications. In this infobrief, we use 'pilot' in contrast to a project. A project may contain one or more pilots, usually in the same province, that are bundled together for fundraising and other purposes. The pilots that make up a project each have their own distinct strategy.

2. We use the criterion of 'having an official agreement with some level of government' as an indicator that the pilot has moved beyond the idea phase and has made some key initial decisions about structure. Because we are using this criterion as a proxy for the stage of development of the pilot and because the regulatory context for REDD+ is complex with no clear determination of which levels of government must or can approve sub-national activities, we considered agreement with any level of government or ministry within Gol sufficient for a pilot to enter our sample.

3. We conducted semi-structured interviews with proponents of all but one project. In this one exception, the project proponent was not available but provided all project documentation and responded to questions by e-mail. Note that some project proponents were implementing more than one pilot.

\section{References}

Agrawal, A., Chhatre, A. and Hardin, R. 2008 Changing governance of world's forests. Science 320: 1460-1462.

Atmadja, S. and Wollenberg, E. 2010 'Indonesia.' In: SpringateBaginski, O. and Wollenberg, E. (eds.) REDD, forest governance and rural livelihoods: the emerging agenda, 73-94. CIFOR, Bogor, Indonesia.

Barr, C., Resosudarmo, I.A.P., Dermawan, A., McCarthy, J., Moeliono, M. and Setiono, B., eds. 2006 Decentralization of forest administration in Indonesia: implications for forest sustainability, economic development and community livelihoods. CIFOR, Bogor, Indonesia.

Boer, R., Sulistyowati, Las, I., Zed, F., Masripatin, N., Kartakusuma, D.A., Hilman, D. and Mulyanto, H.S. 2010 Summary for policy makers: Indonesia second national communication under the United Nations Framework Convention on Climate Change (UNFCCC) (rev. 16 January 2010). State Minister of the Environment, Government of Indonesia, Jakarta, Indonesia.

Butler, R.A. and Laurance, W.F. 2008 New strategies for conserving tropical forests. Trends in Ecology and Evolution 23(9): 469-472.

Climate, Community and Biodiversity Alliance, The (CCBA) 2008 Climate, community and biodiversity project design standards. 2nd ed. CCBA, Arlington, VA, USA.

Center for International Forestry Research (CIFOR) 2010 REDD+ project sites in Indonesia. http://www.forestsclimatechange. org/index.php?id=292 (20 Oct. 2010).

Ecosecurities 2010 The forest carbon offsetting report 2010. EcoSecurities, Dublin, Irish Republic. Available from: http://www.ecosecurities.com/Registered/ ForestCarbonOffsettingReport2010.pdf (20 Oct. 2010).

Government of Indonesia 2010 National strategy REDD: Indonesia readiness phase 2009-2012 and progress in implementation. Ministry of Forestry, Jakarta, Indonesia. http://www.forda-mof. org/uploads/2010/buku\%20redd\%20versi\%20english.pdf (20 Oct. 2010).

Gray, J. 2002 Forest concession policies and revenue systems: country experience and policy changes for sustainable tropical forestry. World Bank Technical Paper, Forest Series, Washington, DC.

Hinrichs, A., Muhtaman, D.R. and Irianto, N. 2008 Forest certification on community land in Indonesia. Deutsche Gesellschaft für Technische Zusammenarbeit, Jakarta, Indonesia.

Peskett, L., Huberman, D., Bowen-Jones, E., Edwards, G. and Brown, J. 2008 Making REDD work for the poor. A Poverty Environment Partnership (PEP) report. http://cmsdata.iucn.org/downloads/ making_redd_work_for_the_poor_final_draft_0110.pdf (20 Oct. 2010).

Resosudarmo, I.A.P. 2004 Closer to people and trees: will decentralisation work for the people and the forests of Indonesia? European Journal of Development Research 16(1): 110-132.

Sills, E., Madeira, E., Sunderlin, W. and Wertz-Kanounnikoff, S. 2009 The evolving landscape of REDD+ projects. In: Angelsen et al. (eds.) Realising REDD+: national strategy and policy options, 265-280. CIFOR, Bogor, Indonesia. 
No. 26

Sunderlin, W.D., Hatcher, J. and Liddle, M. 2008 From exclusion to ownership? challenges and opportunities in advancing forest tenure reform. Rights and Resources Group, Washington, DC.

United Nations Framework Convention on Climate Change (UNFCCC) 2009 Outcome of the work of the Ad Hoc Working Group on Long-term Cooperative Action under the Convention; Draft decision -/CP.15; Policy approaches and positive incentives on issues relating to reducing emissions from deforestation and forest degradation in developing countries; and the role of conservation, sustainable management of forests and enhancement of forest carbon stocks in developing countries. FCCC/AWGLCA/2009/L.7/ Add.6, 15 December 2009. UNFCCC, Bonn.

Voluntary Carbon Standard (VCS) 2008a Voluntary Carbon Standard program guidelines, 2007.1. VCS, Washington, DC.

Voluntary Carbon Standard (VCS) 2008b Voluntary Carbon Standard: tool for AFOLU non-permanence risk analysis and buffer determination. VCS, Washington, DC.

Voluntary Carbon Standard (VCS) 2008c Voluntary Carbon Standard: guidance for agriculture, forestry and other land use projects. VCS, Washington, DC.

Voluntary Carbon Standard (VCS) 2010 Voluntary Carbon Standard: VCS consultation document: proposal for inclusion of peatland rewetting and conservation (PRC) under the VCS Agriculture, Forestry and Other Land Use (AFOLU) Program. VCS, Washington, DC.
Wertz-Kanounnikoff, S. and Kongphan-Apirak, M. 2008 Reducing forest emissions in Southeast Asia: a review of drivers of landuse change and how payments for environmental services (PES) schemes can affect them. Working Paper No. 41. CIFOR, Bogor, Indonesia.

Wertz-Kanounnikoff, S. and Kongphan-Apirak, M. 2009 Emerging REDD+: a preliminary survey of demonstration and readiness activities. Working Paper No. 46. CIFOR, Bogor, Indonesia.

Wunder, S., Engel, S. and Pagiola, S. 2008 Taking stock: a comparative analysis of payments for environmental services programs in developed and developing countries. Ecological Economics 65(4): 834-852.

\section{Acknowledgements}

The lead author gratefully acknowledges the US Fulbright Program, the Indonesian Ministry of Forestry and CIFOR for providing funding, sponsorship, guidance and general support. Funding was also generously provided through a grant to CIFOR by AusAID (Grant 46167). We thank S. Atmadja, Y. Indriatmoko, L. Yuliani, M. Moelino, W. Sunderlin, K. Ginoga and the project developers who accepted to be interviewed and for the generosity with which they shared their time and expertise. We thank the three reviewers for their insightful comments and suggestions on an earlier version of this paper.

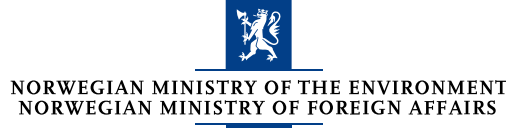
NORWEGIAN MINISTRY OF FOREIGN AFFAIRS MINISTRY OF FOR

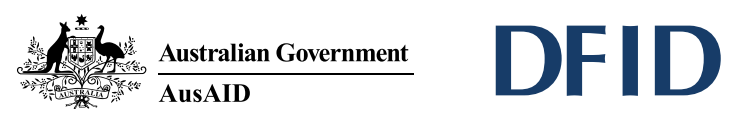

Department for International Development

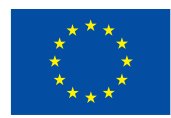

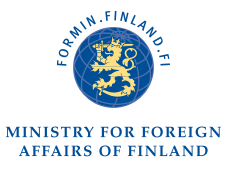

\author{
the Davile Packard \\ FOUNDATION
}
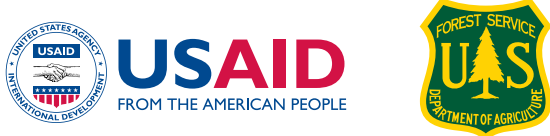